\title{
A Temática Ambiental e o Ensino de Física na Escola Média: Algumas Possibilidades de Desenvolver o Tema Produção de Energia Elétrica em Larga Escala em uma Situação de Ensino
}

\author{
Luciano Fernandes Silva ${ }^{a}$ e Luiz Marcelo de Carvalho ${ }^{b}$ \\ [lufesilva@uol.com.br], [lmarcelo@rc.unesp.br] \\ ${ }^{a}$ Professor Substituto da Universidade Federal de São Carlos-UFSCar \\ Centro de Educação e Ciências Humanas, Departamento de Metodologia do Ensino \\ Rodovia Washington Luiz, Km 235, Caixa Postal 676, São Carlos, SP, CEP 13565-905 \\ ${ }^{b}$ Professor Doutor da Universidade Estadual Paulista-UNESP \\ Instituto de Biociências, Departamento de Educação \\ Av. 24A, 1515, Bela Vista, Rio Claro, SP, CEP 13506-900
}

Recebido em 23 de julho, 2001. Manuscrito revisado em 22 de maio de 2002. Aceito em 7 de julho, 2002.

\begin{abstract}
Diversos setores organizados da sociedade têm chamado a atenção para as alterações provocadas pelo homem na natureza e, dentre estas, destacamos aquelas diretamente relacionadas à produção de energia elétrica em larga escala. O debate em torno desta questão limita-se, na maioria das vezes, aos meios técnicos e acadêmicos. Porém um grande número de pessoas vivencia os principais problemas decorrentes da utilização das diversas tecnologias de produção de eletricidade em larga escala. Dentre as propostas que procuram qualificar um grande número de pessoas para participar deste debate, destacamos o processo educativo. Neste sentido, considerando as sugestões presentes em atuais propostas curriculares, procuramos neste trabalho identificar e sistematizar os principais elementos das discussões ocorridas nos meios técnicos e acadêmicos, que versam sobre produção de energia elétrica em larga escala e a temática ambiental e que poderiam ser convertidos em conteúdo escolar.
\end{abstract}

\begin{abstract}
Many organized sectors in society have pointed out the alterations caused by the human being in nature. Among these charges we would like to highlight those directely related to the production of electric energy in large scale. The debate on the issue is limited, most of times, to tecnicians and academics. However many people feel the problems caused by the use of diverse tecnologies of eletricity production. Considering the orientations of current curricular proposals, we seek in this paper to indentify and systematize the main elements of the discussions being held by technician and academics about electric energy production in large scale, and its relationship with environmental issues, which could be transformed school contents.
\end{abstract}

\section{Introdução}

Vários setores organizados da sociedade têm chamado a atenção para os diferentes níveis de alterações que as organizações humanas impõem aos sistemas naturais como um todo e para os impactos, muitas vezes irreversíveis, que essas alterações podem provocar aos sistemas naturais. Dentre estas interferências, destacamos aquelas diretamente relacionadas com a produção de energia elétrica em larga escala que, sem dúvida, tornam-se mais relevantes na medida em que há um aumento sensível na demanda deste tipo de energia em todo o mundo, sobretudo nos países em desenvolvimento, que ainda possuem um grande contigente populacional sem acesso à energia elétrica produzida em larga escala e aos seus diferentes benefícios. Os benefícios da produção da energia elétrica são facilmente reconhecidos pela população, enquanto os diferentes impactos ambientais advindos da produção desta energia são dificilmente percebidos pelos diferentes grupos sociais.

Historicamente o setor de geração de energia elétrica vem produzindo grandes impactos ambientais e sociais em toda a sua cadeia de produção. Porém apenas recen- 
temente o debate sobre os diferentes impactos ambientais provocados pela geração e utilização desta energia tem feito parte da agenda mundial de discussões. Os problemas decorrentes da degradação ambiental, resultantes das ações antropogênicas sobre a Terra, tiveram maior destaque a partir da Conferência de Estocolmo (UN Conference on the Human Environment), realizada em 1972. Neste encontro enfatizou-se a necessidade de se reaprender a conviver com o planeta Terra, conservando-o e, em alguns casos, preservando-o para garantir a continuidade da vida. Entretanto, foi a partir das discussões da Comissão Mundial para o Meio Ambiente e o Desenvolvimento (World Commission on Environment and Development), documentado no relatório Nosso Futuro Comum (BRUNDTLAND, 1987), que os debates se voltaram para a necessidade de se repensar o modelo de desenvolvimento vigente que orienta as organizações humanas, que tem como um de seus pressupostos básicos o consumo intensivo perdulário de mercadorias e de energia, traduzido de forma mais explícita no chamado american way of life. Os valores que sustentam este modelo de desenvolvimento caracterizam-se, sobretudo, pela exagerada ênfase no aspecto econômico e implica na exploração sem limites dos recursos naturais e na utilização de tecnologias que produzem em larga escala.

Para Leff (2001) a problemática ambiental - a poluição e degradação do meio, a crise de recursos naturais, energéticos e de alimentos - tem sido explicada pela racionalidade econômica e tecnológica dominantes. Contrapondo-se a este modelo de racionalidade produtiva que degrada o ambiente, vários ambientalistas e outros setores organizados da sociedade têm procurado construir uma racionalidade produtiva alternativa. Entretanto, a organização prática desta construção teórica não está limitada apenas pela transformação das condições econômicas, tecnológicas e políticas que determinam as formas dominantes de produção, mas, em última análise...

"estão sujeitas também a certas ideologias teóricas e delimitadas por paradigmas cientificos que dificultam as possibilidades de reorientar as práticas produtivas para um desenvolvimento sustentável." (LEFF, 2001 - p. 61)

No que diz respeito aos debates sobre matrizes de produção de energia elétrica e sobre os impactos ambientais a ela relacionados, podemos destacar dois aspectos: em primeiro lugar, o suprimento eficiente de energia é uma condição básica para o desenvolvimento econômico e social; em segundo lugar, este setor foi responsável por vários desastres ecológicos e sociais ocorridos nos últimos anos.

Com relação aos diferentes impactos provocados pela produção de energia elétrica em larga escala, observa-se que, de uma forma ou de outra, todas as modalidades de produção desta energia provocam alterações na natureza (REIS; SILVEIRA, 2000). Algumas delas, no entanto, provocam maiores taxas de impactos não só ambientais, como também culturais e sociais. Atualmente, vem se discutindo a possibilidade de, a médio e a longo prazo, serem substituídas as matrizes convencionais de produção dessa energia, notadamente aquelas relacionadas aos maiores impactos sociais e ambientais. Neste contexto, algumas pessoas têm chamado a atenção para a utilização mais sistemática de matrizes alternativas, tais como os sistemas fotovoltaicos e eólicos, ou mesmo de matrizes convencionais que usam fontes renováveis para a produção de energia, como é o caso da usinas hidrelétricas de pequeno porte.

Entretanto, os debates sobre a mudança de matrizes geradoras de energia elétrica são, na maioria da vezes, norteados por discussões macroeconômicas e políticas que, neste caso, costumam ter um peso relativamente maior na condução de novos projetos. Podemos citar, por exemplo, a atual política brasileira de investimento em termelétricas movidas a gás, que prossegue, mesmo sofrendo sérias críticas quanto ao tempo de vida útil dos reservatórios de gás boliviano, quanto ao impacto ambiental que a emissão de gases poluentes pode provocar e quanto ao reajuste cambial de tarifas. Além dessas medidas, a história brasileira, no que diz respeito a matrizes geradoras de energia elétrica, tem ainda bastante presente o investimento de bilhões de dólares na compra de usinas térmicas nucleares da Alemanha e dos Estados Unidos da América, o que, segundo Malheiros (1996) e Rosa et al. (1988), se deu mediante uma política equivocada de transferência de tecnologia.

Recentemente a sociedade brasileira vivenciou problemas relacionados à escassez de suprimento de energia elétrica (vide Resolução $\mathrm{n}^{\circ} 22$, de 04 de julho de 2001 da Câmara de Gestão da crise de Energia Elétrica e Medida Provisória $n^{o}$ 2.198-3, de 29 de junho de 2001) e este fato tem levado o governo a flexibilizar as exigências da legislação ambiental para a implantação de novos projetos de produção de energia elétrica. $\mathrm{O}$ Brasil, que possui uma das mais modernas legislações ambientais do mundo (Resoluções do Conselho Nacional do Meio Ambiente - CONAMA - no 001, de 23 de janeiro de 1986, e 237, de 19 de dezembro de 1997 e, para empreendimentos do setor elétrico, de forma complementar, $\mathrm{n}^{\circ} 006$, de 16 de setembro de 1987), promulgou em 2001 uma nova resolução (Resolução 279, de 27 de junho de 2001) que flexibiliza as exigências da legislação vigente, pois estabelece prazos máximos para a avaliação dos impactos ambientais dos novos empreendimentos e um relatório de impactos ambientais simplificado para pequenas hidrelétricas. Entretanto, esse prazo depende de inúmeros fatores interligados e complexos, o que pode requerer um estudo e uma avaliação mais demorados. Assistimos, deste modo, ao governo 
cedendo às pressões das empreiteiras responsáveis pela construção de empreendimentos de geração de energia e às pressões políticas que exigem uma solução rápida para o problema da escassez de energia em nosso país.

Neste sentido, será necessária uma maior mobilização de amplos setores da sociedade para evitar que soluções de curtíssimo prazo precipitem diversas ações que possam comprometer um planejamento mais adequado para o futuro, como a manutenção de níveis mínimos de conservação ambiental.

Todavia, essas propostas e os debates em torno dessa questão ficam restritos, na maioria das vezes, aos meios técnicos e acadêmicos. Porém, um grande contingente populacional experimenta as decisões tomadas em torno dela.

O processo educativo tem sido visto como uma das possibilidades para equipar um grande número de pessoas com informações e competências para participar deste debate emergente e cada vez mais presente na nossa sociedade. Neste sentido, consideramos que cabe ao ensino de ciências naturais, em particular, dotar os alunos de chaves essenciais para a solução de questões científicas e técnicas do cotidiano, e propiciar-lhes o desenvolvimento de atitudes e métodos de pensamento próximos aos dos cientistas. (ASTOLFI; DEVELAY, 1998 e SAVIANI, 2000)

A incorporação dessas questões no currículo escolar pode proporcionar ao ensino das ciências naturais, em particular, um contexto para a discussão de alguns dos aspectos ambientais, sociais, econômicos, políticos, históricos, éticos e estéticos diretamente relacionados com a Ciência e suas diversas aplicações. Além disso, a discussão de alguns desses tópicos, em algum momento do processo de ensino-aprendizagem, pode auxiliar a amenizar o "mal-estar" (MATTHEWS, 1994) que existe em aulas de ciências naturais, em que se recitam fórmulas longe de um contexto ou se privilegia a quantidade de informações e não a profundidade com que se examinam os princípios teóricos e suas implicações sociais, ambientais, econômicas e históricas.

Segundo Silva e Saad (1998) e Monteiro e Medeiros (1998), os professores de ciências naturais, especificamente de Física, têm-se utilizado dos manuais de ensino de forma indiscriminada, como única referência para estruturar e dirigir suas aulas. Entretanto, esses manuais, em sua maioria, não sugerem nenhuma atividade educativa relevante ligada aos grandes debates acerca dos diferentes significados do conhecimentos científico e suas diferentes aplicações.

Para Bastos (1998) e Krasilchik (1987), na maioria das vezes, os alunos não têm sido levados a discutir em sala de aula as causas dos fenômenos e as diferentes implicações do conhecimento que estão estudando. Usualmente apresentam-se as ciências naturais apenas em seus resultados finais, freqüentemente traduzidos em informações estruturadas em expressões matemáticas. Não desconsiderando a importância da linguagem ma- temática no ensino de ciências naturais, fundamentalmente no ensino de Física, acreditamos que a prática de ensino nesta área deve ser enriquecida, a fim de propiciar aos estudantes a capacidade de coletar dados e informações relativos a fenômenos vivenciados em seu cotidiano, analisar esses dados, interpretando os conceitos fundamentais e relacionando-os com os fenômenos com os quais se deparam no dia-a-dia.

A possibilidade de enriquecer as aulas de Física com a exploração de outros aspectos, além dos técnicos, durante a abordagem do conteúdo que trata da produção de energia elétrica em larga escala, é também sugerida na Proposta Curricular para o Ensino de Física do Estado de São Paulo (SÃO PAULO, 1992) e nos Parâmetros Curriculares Nacionais para o Ensino Médio (BRASIL, 1999). No texto da Proposta Curricular para o Ensino de Física (SÃO PAULO, 1992) indica-se, dentre os objetivos apresentados para o ensino de Física na escola média, a analise das várias formas de produção de energia elétrica em função de parâmetros como: custos, benefícios e impactos sobre o meio ambiente. (SÃO PAULO, 1992, p.36)

Entretanto, as diferentes possibilidades de explorar outros aspectos deste tema em sala de aula podem ser limitadas por vários fatores, dentre os quais: a urgência do professor em cumprir um certo número de conteúdos curriculares, o despreparo do professor, a falta de participação e interesse de alunos pouco estimulados, a compreensão que os alunos têm a respeito da "produção de energia elétrica em larga escala", a dificuldade de se desenvolver um tema tão complexo em sala de aula e a falta de material didático adequado. A respeito destes dois últimos itens, pudemos observar, como professor de Física trabalhando especificadamente com alunos do nível médio de uma escola pública da Diretoria de Ensino de Araraquara-SP, que boa parte dos manuais escolares não apresentam nenhuma consideração mais consistente sobre as discussões relacionadas à produção de energia elétrica e seus diferentes impactos.

A partir dessa constatação e considerando as diferentes possibilidades de explorar o tema "produção de energia elétrica em larga escala", procuramos refletir sobre em que medida as análises realizadas por cientistas, técnicos e outros grupos sociais sobre este tema, poderiam ser recontextualizadas em conteúdos escolares. De forma mais específica, nosso questionamento pode ser assim traduzido: Que possibilidades o conteúdo eletricidade, mais especificamente "produção de energia elétrica em larga escala", oferece para o desenvolvimento de trabalhos com educação ambiental em sala de aula?

Na busca de respostas para esta questão, surgiu a possibilidade de explorar de forma mais sistematizada este tema em uma dissertação de mestrado concluída em 2001 (SILVA, 2001). Um dos objetivos do trabalho consistiu em verificar algumas possibilidades de recontextualizar em conteúdo escolar alguns dos principais 
debates que ocorrem nos meios técnico e científico, que relacionam a constante preocupação da sociedade em produzir energia elétrica em larga escala com as mais recentes preocupações diretamente associadas às diversas problemáticas ambientais. Neste artigo apresentamos os resultados que obtivemos com o desenvolvimento da primeira etapa da pesquisa.

\section{Objetivos da pesquisa e pro- cedimentos utilizados}

Considerando-se a questão anteriormente levantada, um dos objetivos da pesquisa, explorado neste artigo, constituiu-se justamente em identificar na literatura os elementos que permitem sistematizar as discussões que ocorrem nos meios técnicos e acadêmicos relacionados à temática ambiental e à produção de energia elétrica em larga escala, no sentido de fornecer subsídios para o processo de socialização dos conhecimentos científicos através do trabalho em sala de aula.

O procedimento mais adequado para a caracterização deste quadro foi o de consulta à bibliografia que discute aspectos da relação entre produção de energia elétrica e impactos ambientais. Este levantamento bibliográfico possibilitou, assim, a sistematização de informações sobre esta realidade oferecendo um quadro referencial básico em termos de conteúdos e possíveis abordagens para o planejamento de atividades em sala de aula relacionadas com esta temática.

\section{Produção de energia elétrica em larga escala}

Considerando-se a possibilidade de socializar o conhecimento produzido e sistematizado pela ciência através do trabalho educativo, seria interessante que fossem abordados em sala de aula temas relacionados à produção de energia elétrica em larga escala e a temática ambiental. Neste sentido, parece-nos pertinente considerar, entre outras, questões relacionadas com os atuais modelos de produção econômica, com o significado e pertinência desta demanda atual de energia, com o perfil de gasto energético de diferentes países, com as possibilidades de alteração neste quadro. O tratamento de questões como estas nos permite, em última análise, discutir com os alunos ações relacionadas com os modelos de desenvolvimento.

É importante salientar que diferentes degradações ambientais têm sido realizadas em nome do "progresso" e do "desenvolvimento", porém, nem sempre associados à melhoria da qualidade de vida da maioria da população. Para Brügger (1994) esses conceitos, muitas vezes, não passam de eufemismo para designar crescimento desordenado, traduzido em "modernização" da pobreza. (BR $\ddot{U} G G E R, p .66$ - 1994)
Os valores que sustentam o padrão de desenvolvimento ainda vigente em nossa sociedade dão exagerada ênfase ao aspecto do crescimento econômico, sem considerar que a exploração descontrolada dos recursos naturais implica grandes prejuízos ambientais e humanos. Neste sentido, podemos questionar a grande voracidade de energia que as sociedades urbanas modernas requerem para sua sobrevivência. Isso também implica revermos nosso padrão de consumo. Conforme Reis e Silveira (2000), em países como o Brasil, o aumento de um ponto percentual no PIB significa, geralmente, um aumento de $30 \%$ no consumo de energia.

Entretanto, o crescimento da demanda por energia elétrica deveria permitir um maior investimento em plantas energéticas menos prejudiciais aos meios sociais e naturais. Mas, ao contrário, observa-se que, na maior parte do mundo, as centrais energéticas que usam combustíveis fósseis ainda prevalecem, sobretudo devido ao seu preço convidativo (carvão fóssil, petróleo). Observa-se que projetos mais adequados a um "paradigma sustentável" permanecem na condição experimental, sobretudo devido à ênfase ao aspecto puramente econômico. Essa situação poderia ser revertida, caso fossem agregados ao valor da energia os diferentes impactos provocados durante seu processo de produção.

Para que possamos compreender quais são os processos de produção de energia elétrica menos prejudiciais aos meios naturais e humanos, precisamos identificar os principais processos de transformação de uma fonte de energia primária em elétrica e, dentre estas fontes, quais são as que trazem menores impactos para os meios social e ambiental.

Dada a complexidade do tema, optamos por apresentar algumas das mais conhecidas possibilidades de produzir energia elétrica em larga escala. Nesta apresentação, são destacados aspectos diretamente ligados aos benefícios e prejuízos advindos de cada forma de obtenção de energia elétrica.

Os principais processos de transformação de uma fonte primária de energia em energia elétrica podem ser divididos em três grandes grupos: transformação da energia cinética do deslocamento de grandes massas (água e ar) em energia mecânica e desta, por processos eletromagnéticos, em energia elétrica; transformação direta da energia solar em energia elétrica, através do uso de células fotovoltaicas; transformação da energia química liberada na combustão ou na fissão de elementos radioativos em energia mecânica e desta, por processos eletromagnéticos, em energia elétrica.

Em última análise, a partir desses processos de transformação, as principais formas de geração de energia elétrica em larga escala podem assim ser divididas: 1-Hidrelétricas; 2-Termelétricas (Movidas a gás natural, carvão fóssil, derivados de petróleo e biomassa); 3Usinas Nucleares; 4-Fontes alternativas (energia solar e eólica). 
Dada a restrição de espaço e o objetivo deste texto, procuraremos abordar algumas das principais características de cada uma das formas de gerar eletricidade em larga escala, anteriormente mencionadas sem, contudo, realizar uma análise exaustiva de cada uma delas.

\section{III.1 Geração de energia elétrica por hi- drelétricas}

A energia elétrica produzida em larga escala no Brasil provém quase que exclusivamente de geradores hidrelétricos. Segundo Reis e Silveira (2000), 90\% de toda a produção em 1995 foi gerada por hidreletricidade.

Esta característica do país está imediatamente relacionada ao grande potencial hídrico existente e também à carência de outras fontes primárias tais como o petróleo, o gás natural e o carvão fóssil. Em outros países, outras fontes de energia primária têm sido utilizadas, de acordo com as características peculiares locais. Segundo Rosa et al. (1998), os dados referentes ao ano de 1994 mostram que na Inglaterra $60,7 \%$ da energia elétrica era produzida a partir de termelétricas movidas a carvão fóssil; já na França mais de $75 \%$ provinha de usinas nucleares; e na Argentina $63,5 \%$ da energia era gerada em termelétricas movidas a gás natural e óleo.

Percebe-se que o Brasil, comparado a outros países, possui uma característica singular em seu parque de produção de energia elétrica. A produção através de hidrelétricas resultou ao país custos baratos de energia do ponto de vista estritamente econômico. Além disso, o país não possui nenhuma dependência externa quanto ao combustível utilizado, pois hidrelétricas utilizam-se da água das chuvas acumuladas em rios e lagos, e esta não pode ser comprada de nenhum outro país.

No Brasil, os macroprojetos de hidrelétricas possuem em comum imensos reservatórios de água, cuja finalidade é determinar uma produção estável de energia elétrica durante todo o ano. Devido às características de sazonalidade do regime pluvial do país, foi construído um sistema de transmissão de energia que interliga atualmente todas as regiões. Deste modo, quando há falta de água nos rios do norte ou nordeste, pode-se transferir a energia excedente do sul ou sudeste. Quando uma determinada região coloca mais potência na rede, está cedendo água indiretamente à outra região.

Além disso, os grandes projetos hidrelétricos para geração de eletricidade foram considerados durante muito tempo como uma das formas mais limpas e menos agressoras do meio ambiente, principalmente devido à taxa zero de emissões de gases no processo final de produção.

Atualmente, essa visão tem sido questionada, sobretudo devido aos impactos sociais e ambientais. A construção de uma barragem, do ponto de vista sócioambiental, traz vantagens e desvantagens, custos e benefícios. Sabemos que grandes reservatórios de água provocam a inundação de uma vasta área terrestre, com nítidos prejuízos para a fauna e flora locais, deslocamento de populações ribeirinhas, desaparecimento de terras férteis, destruição de tesouros culturais e emissão de gases estufa (metano), provenientes da decomposição de material orgânico.

Desde a implantação das primeira hidrelétricas no Brasil, tornaram-se evidentes as modificações nas comunidades de peixes ocasionadas pela construção de barragens para as grandes usinas. Com efeito, ao interceptar o fluxo d'água de um rio, além de causar inúmeras modificações num amplo espectro de atividades e processos ao longo da bacia hidrográfica, as represas interferem nos processos de evolução dos diferentes organismos aquáticos daquele ecossistema (BRANCO E ROCHA, 1977).

Existem alguns estudos sobre os impactos sociais decorrentes da construção de projetos hidrelétricos brasileiros, entre os quais Sigaud (IN ROSA E OUTROS, 1988) destaca os efeitos negativos da barragem Sobradinho, tais como o aumento do desemprego, a marginalidade e a ocupação desordenada de áreas de preservação com crescente pressão sobre os ambientes naturais.

Atualmente, alguns setores técnicos e científicos reconhecem que os grandes empreendimentos hidrelétricos não são os mais adequados, dentro de um paradigma de desenvolvimento sustentável. Muito se tem falado na possibilidade de incentivar a construção de usinas hidrelétricas menores e locais (REIS E SILVEIRA, 2000), de modo a diminuir os impactos socioambientais e a descentralizar o setor de geração de energia elétrica.

Atualmente tem-se discutido muito no Brasil sobre a necessidade de se diversificar o parque energético atual. Muito se tem falado nas termelétricas, principalmente aquelas que utilizam o gás natural como combustível. Segundo Rosa et al. (1998), o setor elétrico brasileiro atravessa, nos últimos anos, momentos de intensas transformações. Diariamente somos informados sobre privatizações no setor, novas maneiras de se obter energia, investimentos do país em usinas nucleares e termelétricas movidas a gás natural, saturamento do sistema em horários de pico de consumo, aumentos de tarifa, acumulação de diversos problemas no setor, o perigo de blecautes e o impacto ambiental que determinada matriz energética pode provocar. Porém, temos observado que o debate e mesmo a análise do que vem ocorrendo no Brasil e no mundo têm ficado muito distantes da sala de aula. 


\section{III.2 Geração de energia elétrica por ter- melétricas}

A energia elétrica produzida por termelétricas é a mais utilizada em todo o mundo e isto se deve, sobretudo, aos aspectos econômicos, tendo em vista que a maioria destas usinas utilizam combustíveis fósseis. Existe, ainda hoje, uma grande disponibilidade de petróleo e carvão no mundo, característica que reduz muito o preço destes combustíveis e os torna atraentes do ponto de vista de uma análise estritamente financeira. Além disso, alguns países possuem enormes jazidas de combustíveis fósseis, característica que reduz muito o custo da energia produzida. Na China e na Índia, por exemplo, existem imensas jazidas de carvão mineral que são aproveitadas mediante a construção de usinas termelétricas próximas a estas fontes de combustível.

No Brasil, a geração de eletricidade por termelétricas ainda é incipiente. A maior concentração de usinas que utilizam o óleo combustível e o carvão fóssil encontra-se no Sul do país, mas representa apenas $2 \%$ do total da energia produzida.

Outros combustíveis também são utilizados no Brasil para gerar eletricidade em termelétricas. Atualmente, devido à crise energética que o país enfrenta, a possibilidade de utilização do gás natural importado da Bolívia para a geração de eletricidade tem sido discutida. Além disso, o curto prazo necessário para a construção deste tipo de termelétrica, em comparação com hidrelétricas, tem sido outro argumento usado a seu favor, dada a necessidade do país em construir rapidamente outras usinas geradoras de eletricidade para suprir a demanda crescente deste produto.

O processo básico de funcionamento de uma termelétrica está baseado na conversão de energia térmica em energia mecânica e desta, através de processos eletromagnéticos, em energia elétrica. Uma termelétrica pode utilizar diversas fontes de energia primária para a obtenção de calor, dentre as quais gás natural, carvão fóssil, derivados de petróleo e biomassa. Dependendo do tipo da fonte utilizada, teremos maiores ou menores impactos provocados por este tipo de gerador.

Geradores termelétricos que utilizam fontes nãorenováveis de energia primária (carvão fóssil, gás natural e derivados de petróleo) são os que causam maiores impactos ambientais, pois, no processo de queima desses combustíveis, grandes quantidades de gases poluidores são lançados à atmosfera. $\mathrm{O}$ principal produto da combustão dessas fontes é o $\mathrm{CO}_{2}$, um dos principais agentes do processo de aquecimento global (efeito estufa). As quantidades lançadas na atmosfera vão depender das características próprias de cada usina e do tipo de combustível utilizado.

Além do efeito estufa, outros impactos estão diretamente associados às emissões de gases por termelétricas, tais como a chuva ácida, que ocorre devido ao aumento da concentração de dióxido de enxofre $\left(\mathrm{SO}_{2}\right)$ e óxidos de nitrogênio $\left(\mathrm{NO}_{x}\right)$ na atmosfera.

Além de todos os compostos gasosos emitidos por centrais termelétricas, ressalta-se ainda, no caso da utilização do carvão fóssil, a importância negativa das emissões de cinzas carregadas de metais pesados. As cinzas geradas e emitidas pelas termelétricas são espalhadas pela ação dos ventos em uma grande área territorial, precipitando-se sobre solo, rios e lagos, provocando degradações ambientais.

Dentre as fontes não-renováveis de energia utilizadas em termelétricas, o gás natural é a que apresenta menores taxas de poluição atmosférica, sendo seu principal produto o $\mathrm{CO}_{2}$ (dióxido de carbono). No trabalho de Reis e Silveira (2000), o gás natural é apresentado como uma fonte transitória entre os derivados de petróleo, o carvão e as tecnologias menos agressoras do meio ambiente.

As termelétricas podem também usar como combustível a biomassa, como, bagaço de cana-de-açúcar, madeira de florestas energéticas, etanol, carvão vegetal e outros. A biomassa como combustível em termelétricas é hoje considerada uma das principais alternativas de fonte renovável para produção de eletricidade em larga escala no futuro.

Um ponto extremamente favorável à utilização da biomassa está ligado aos pequenos índices de emissões de $\mathrm{CO}_{2}$, em certos casos bem próximos de zero. Segundo Reis e Silveira (2000), se a biomassa for produzida de forma sustentável, praticamente todo $\mathrm{o}^{\mathrm{CO}_{2}}$ liberado na queima do material será extraído da atmosfera durante a fotossíntese realizada pelo cultivo de material de reposição.

Porém, uma grande preocupação quanto à difusão do uso da biomassa está na perda da biodiversidade e de solos para a agricultura de alimentos. Além disso, a sustentação de uma monocultura exige a utilização intensiva de defensivos agrícolas que poluem o solo e a água.

No Brasil, o uso mais promissor da biomassa para gerar eletricidade está na utilização do resíduo de canade-açúcar e da biomassa florestal. As indústrias do setor sucroalcooleiro têm produção sazonal, utilizam vapor na produção e, ao mesmo tempo, na geração de eletricidade, cujo excedente pode ser vendido ao setor elétrico.

Outra possibilidade de gerar energia elétrica muito utilizada em todo o mundo é através das usinas nucleares, que também seguem o perfil fundamental do funcionamento das termelétricas. Porém, algumas particularidades técnicas, sociais e ambientais, diretamente relacionadas a este tipo de geração elétrica, nos permitem um tratamento mais elaborado desta questão. A importância de ampliarmos os debates, através de atividades educativas, sobre o significado da construção de usinas nucleares para a produção de energia elétrica também justifica o desenvolvimento do próximo item. 


\section{III.3 Geração de energia elétrica através de usinas nucleares}

De modo geral, nenhuma outra forma de produção de energia elétrica enfrenta tantas pressões mundiais contrárias à sua utilização quanto as usinas nucleares. Segundo Rosa e Shaeffer (in Rosa e outros, 1988), isto se deve, principalmente, ao forte impacto na percepção mundial causada pelos acidentes de Three Mile Island (EUA - 1979) e Chernobyl (Ucrânia - 1986). Países que possuem um grande número de reatores, como a Alemanha, já anunciaram que pretendem fechar a maioria de suas usinas nucleares. Esta percepção negativa da população, quanto ao uso desta tecnologia, levou o governo brasileiro a realizar acordos absolutamente sigilosos na área nuclear (Brasil-EUA e Brasil-Alemanha).

No Brasil, segundo Rosa et al (1988), o Programa Nuclear foi alvo de críticas de diferentes setores da sociedade e, neste caso, a Sociedade Brasileira de Física e a Sociedade Brasileira para o Progresso da Ciência desenvolveram importantes trabalhos críticos sobre os diferentes riscos trazidos por reatores nucleares. Segundo o autor, também encontram-se entre seus opositores:

“... intelectuais, cientistas, em-
presários, representantes de classe e
políticos das mais diversas conotações
ideológicas, cobrindo uma ampla faixa de
posiçóes" (ROSA E OUTROS - 1988 - p.
43)

Goldemberg (1998) situa a crítica, sobretudo, no montante dos investimentos requeridos para a implementação dessas usinas, na segurança do reator, no problema da deposição dos resíduos radioativos, que devem ser armazenados por milhares de anos em reservatórios subterrâneos profundos, contidos em cimento, betume ou resinas, ou vetrificação e armazenagem em formações geológicas estáveis na terra ou no leito do mar, e no montante de recursos financeiros necessários para a desativação das instalações nucleares.

Com relação à questão específica da segurança, ocorrências de acidentes em usinas nucleares são extremamente pequenas, cerca de $10^{-4}$ por reator/ano. Porém, as conseqüências de um acidente desta natureza são extremamente graves, pois envolve a emissão de radiação. Pessoas que estiveram em contato direto com altos níveis de radiação estão sujeitas a inúmeros problemas de saúde devido a modificações genéticas, que podem ser transferidos aos seus descendentes por inúmeras gerações.

A questão dos resíduos radioativos, talvez hoje seja o maior desafio desse tipo de tecnologia. Anualmente, milhares de toneladas de resíduos são dispostas em grandes depósitos, devido ao alto índice de radiação residual. Atualmente, estão sendo pesquisadas várias maneiras de estocar esses materiais com segurança e de minimizar a radiação residual nos dejetos das usinas.
No que se refere ao aspecto econômico, podemos destacar também que este tipo de tecnologia é dominado por poucos países. Neste caso, apenas alguns países, como o Japão, os EUA e a Rússia possuem a tecnologia necessária para processar o enriquecimento do material radioativo de tal forma que possa ser utilizado em reatores nucleares. Neste sentido, muitos países que adotam este tipo de tecnologia acabam dependentes dos países mais industrializados.

Não podemos descartar também os problemas políticos que envolvem a questão da proliferação de armas nucleares de destruição em massa. Os países que dominam o ciclo de enriquecimento radioativo são tecnicamente capazes de produzi-las.

Por último, destacamos que o tipo de reator utilizado no Brasil, um PWR (Pressurized Water Reactor), utiliza em um dos seus sistemas de refrigeração a água captada de fontes externas (mar). Não há estudos sistematizados, mas o principal problema ambiental decorrente da utilização desta água está no aumento da temperatura que ela sofre, ocasionando possíveis impactos na microflora e microfauna da região costeira de Angra dos Reis.

Contudo, a geração de energia elétrica em larga escala através de elementos radioativos em usinas nucleares constitui-se numa das mais importantes fontes de produção mundial. Malheiros (1996) aponta até 1996 a existência de 437 unidades em operação e 39 em construção, em todo o mundo. Segundo Goldemberg (1998), em 1992 a eletricidade produzida por usinas nucleares representava $17 \%$ da eletricidade mundial e $23 \%$ nos países da OECD (Organização para Cooperação e Desenvolvimento Econômico)

Os EUA têm a maior concentração de usinas nucleares do planeta, com aproximadamente 109 reatores, e, segundo Rosa et al. (1998), a França possui 56 reatores, responsáveis por mais de $75 \%$ da energia elétrica gerada no país. Na América Latina, somente México, Brasil e Argentina possuem usinas nucleares, com dois reatores cada um. No Brasil esta fonte representa apenas $3 \%$ da energia gerada.

Os materiais radioativos (urânio, tório, plutônio, etc), utilizados como combustíveis nestas usinas, estão classificados como fontes de energia não-renováveis. Porém, diferentemente de outras fontes de energia nãorenovável, não há emissão de gases e cinzas na utilização do combustível radioativo em usinas nucleares. Para Reis e Silveira (2000), a energia nuclear, embora não seja renovável, poderá um dia se constituir, caso todos os sérios problemas levantados sejam solucionados, numa das principais alternativas futuras de geração de energia elétrica, principalmente por não gerar emissões diretas de material poluente. 


\section{III.4 Geração de energia elétrica através de energia solar e eólica}

Tecnologias que permitem a conversão de energia solar e eólica em energia elétrica são as mais adequadas em um paradigma de desenvolvimento sustentável. Além das taxas nulas de emissões de gases no processo final da produção, esses geradores utilizam energia renovável e abundante.

O maior número de geradores eólicos e fotovoltaicos está concentrado nos EUA e na Europa e, dentre os países em desenvolvimento, destaca-se a Índia.

O uso do vento na produção de energia elétrica foi a resposta da Dinamarca à crise do petróleo nos anos de 1970. Desde então, este país vem não só utilizando esta tecnologia em larga escala como também produzindo e exportando equipamentos para usinas eólicas no mundo inteiro.

No Brasil, existem registros de experiências realizadas em pontos isolados do território. Segundo Reis e Silveira (2000), no Estado do Ceará já foram identificadas diversas áreas adequadas para a instalação de usinas eólicas, porém o país só possui 4 projetos-piloto iniciados nos últimos anos: Fernando de Noronha com $75 \mathrm{KW}$, Minas Gerais com $1 \mathrm{MW}$, Ceará com 1,2 MW e, finalmente, Recife com $22 \mathrm{KW}$.

O governo brasileiro anunciou no final de 2001, através da ANEEL - Agência Nacional de Energia Elétrica - a autorização de instalação de mais 23 usinas eólicas no país. Elas irão ampliar em 1907 MW a capacidade de potência instalada de geração de energia elétrica do país, sobretudo, no Nordeste, região que abrigará todos esses empreendimentos. As novas usinas se somarão a outras 20 e ao todo, as 48 usinas eólicas garantirão mais $3.680 \mathrm{MW}$ ao sistema elétrico até 2005. De modo geral, a energia fotovoltaica e eólica tem sido utilizada na maioria dos países do mundo para suprir pequenas cargas em locais afastados, onde a extensão da rede se torna extremamente inviável economicamente. Esta tecnologia também é utilizada para suprir de energia pequenos sistemas de comunicação ou radares. No Brasil, os sistemas fotovoltaicos ainda se resumem praticamente a pequenos sistemas isolados, que fornecem energia para apenas poucas casas.

Entretanto, quanto aos geradores fotovoltaicos, Pereira e Colle (1997) destacam que, apesar de inexpressiva, a longo prazo esta tecnologia passará a ser uma das principais fontes de energia do mundo.

Para Reis e Silveira (2000), o grande ponto positivo diretamente ligado a este tipo de tecnologia (fotovoltaica) está na taxa nula de emissão de poluentes. Segundo os autores, esta atração deve-se, sobretudo, ao modo limpo de gerar eletricidade por sistemas fotovoltaicos. Nas palavras de Chambouleyron (1989),

"A eletricidade solar fotovoltaica é considerada a tecnologia energética ótima(...)O processo de geração, executado por dispositivos semicondutores, não tem partes móveis, não produz cinzas nem outros resíduos $e$, por não liberar calor residual, não altera o equilíbrio da biosfera(...) Como não envolve queima de combustiveis, evita por completo o efeito estufa." (CHAMBOULEYRON, 1989 - p.38).

Porém, a utilização em larga escala dessas tecnologias (solar e fotovoltaica) ainda depende de um maior aperfeiçoamento técnico, pois o rendimento dos equipamentos ainda é relativamente baixo. Outro fator de restrição é o custo final destes geradores, porque a tecnologia usada é de ponta e ainda não existe produção em larga escala.

Os principais impactos ligados à produção de energia elétrica em larga escala, utilizando essas tecnologias, estão vinculados à extração dos materiais necessários para a fabricação das estruturas, caso dos sistemas fotovoltaicos que utilizam, na maioria das vezes, o silício. Além disso, geradores elétricos que utilizam a energia solar e eólica, devido a algumas características técnicas, podem armazenar energia na forma de corrente contínua em baterias, para depois convertêla em corrente-alternada. Cuidados com a deposição dos equipamentos, após sua vida útil, são necessários devido ao alto índice de materiais tóxicos (metais pesados) presentes nas baterias. Além disso, há o impacto na paisagem, alterações nos padrões do uso da terra, questões relacionadas à proteção de aves e à poluição sonora, estes últimos ligados aos sistemas eólicos.

No entanto, para muitos ambientalistas, esses impactos ambientais são aceitáveis, quando comparados com os provocados por outras matrizes geradoras de energia elétrica em larga escala.

\section{Produção de energia elétrica em larga escala e a temática ambiental: aspectos relevan- tes para atividades de educa- ção ambiental}

De acordo com a análise bibliográfica que realizamos, discussões em sala de aula que abordem a produção de energia elétrica em larga escala e a temática ambiental devem considerar as principais formas técnicas de gerar energia elétrica em larga escala e sua comparação em termos de custos financeiros, políticos, sociais e ambientais. A principal vantagem desta abordagem múltipla do tema está na oportunidade de reconhecer os inúmeros e complexos condicionantes presentes no setor de geração de energia elétrica e as oportunidades que existem para o seu desenvolvimento. 
A abordagem desses diferentes aspectos não significa minimizar os conteúdos básicos e fundamentais para a compreensão dos processos físicos com os quais convivemos no nosso dia-a-dia. O que se propõe, e o que se espera é que cada um dos diferentes aspectos abordados alimentem-se mutuamente, garantindo em sala de aula uma visão integrada da realidade.

Neste sentido, uma situação ou problema de natureza social e interdisciplinar pode contribuir para que o professor desenvolva os conteúdos mais técnicos da Física. Ao mesmo tempo, a compreensão desses conteúdos possibilitam ao professor um aprofundamento no conhecimento dos fenômenos naturais, podendo oferecer aos alunos condições de análise e de interpretação de fenômenos sociais mais complexos. O importante é que se garanta que, ao final do processo escolar, os alunos tenham entrado em contato com aspectos básicos de fenômenos naturais e da realidade social.

Neste sentido, acreditamos que para tratar, ao desenvolvermos atividades de educação ambiental, de aspectos da aplicação do conhecimento científico diretamente relacionado com a temática ambiental, um dos possíveis e desejáveis caminhos seja o de considerar três dimensões:

uma primeira dimensão, relacionada com a natureza dos conhecimentos a serem trabalhados;

uma segunda dimensão, relacionada com valores éticos e estéticos, envolvendo a questão da natureza;

e, por fim, um conjunto de objetivos relacionados com a dimensão política, no sentido de preparar o indivíduo para ações concretas na busca de soluções para os problemas ambientais (CARVALHO, 2000).

Uma possibilidade muito rica ao abordar o conteúdo "produção de energia elétrica em larga escala" está no reconhecimento e questionamento da necessidade de produção crescente de energia elétrica e, em contrapartida, nos seus diferentes impactos sociais e ambientais. Neste sentido, cabe considerar nestes trabalhos os diferentes conceitos de "desenvolvimento" e "progresso", sobretudo o modelo de crescimento "insustentável" vigente em diversas sociedades. Algumas dessas sociedades são marcadas por um consumismo insustentável, enquanto grandes parcelas da população encontram-se à margem de qualquer possibilidade de usufruir dos benefícios que o uso racional da energia elétrica oferece.

No caso específico de países "emergentes", como o Brasil, alguns dados mostram que a retomada do crescimento econômico significa, geralmente, um aumento vertiginoso no consumo de energia (REIS E SILVEIRA, 2000) e esta, por sua vez, numa grande pressão no setor de geração de energia elétrica. Neste caso, é importante que se considerem, durante a análise do aumento da demanda por energia, duas questões específicas: de um lado, temos mais pessoas sendo incluídas como consumidoras de energia; mas, de outro, existem aquelas que passam a utilizar a energia em demasia, muitas vezes atendendo aos apelos de um estilo de vida subordinado à moral do mercado e do consumo, o qual prega o "imprescindível" uso dos mais variados aparelhos que, diante da primeira crise energética, se tornam sucatas inúteis.

De qualquer forma, em países com taxas positivas de crescimento populacional, é previsto um aumento da produção de energia elétrica. Neste caso, devem-se analisar as melhores alternativas em termos de custos sociais, ambientais, econômicos e políticos. O exemplo do parque de geração brasileiro expressa bem esta análise, pois, para crescer, necessita da produção de valores crescentes de energia e, além disso, domina de modo satisfatório a tecnologia de geração por hidrelétricas. Porém, os recursos naturais (rios) ainda não utilizados encontram-se na região norte do país, ou seja, em pleno território da floresta amazônica. Neste caso, o aluno pode ser incentivado a compreender as possíveis conseqüências decorrentes da destruição de parte da floresta, mas também pode ser levado a pensar em soluções ou alternativas para a produção de energia elétrica.

Dentre as alternativas de produção de energia elétrica em larga escala, muito tem se falado nas termelétricas movidas a gás natural. Porém, elas são, sem dúvida, uma opção pouco favorável aos sistemas naturais, a começar pelos altos índices de $\mathrm{CO}_{2}$ emitidos pela queima deste combustível.

Termelétricas movidas a carvão fóssil ou derivados de petróleo constituem-se, dentre as principais alternativas de produção de energia elétrica em larga escala, as menos favoráveis aos meios naturais. A queima desses combustíveis pode ocasionar grandes prejuízos aos sistemas naturais e humanos, como a liberação de grandes quantidades de gases tóxicos, com especial destaque aos altos níveis de $\mathrm{CO}_{2}$, além de cinzas carregadas de metais pesados. Ademais, a extração e o transporte desses combustíveis podem ocasionar grandes desastres ambientais, tais como o vazamento de petróleo e a devastação das áreas naturais das quais se extrai o carvão fóssil. Porém, alternativas aos combustíveis fósseis ainda esbarram em análises estritamente econômicas, tais como aquelas que consideram exclusivamente o baixo preço do combustível.

No caso específico das usinas nucleares, opção utilizada por inúmeros países, existe o grave problema do destino do lixo nuclear. Esta opção, apesar de atraente para vários técnicos, sofre a objeção de grandes parcelas da população, sobretudo pelo movimento ambientalista organizado que chama a atenção para os graves problemas ambientais ocasionados pelo acúmulo de resíduos nucleares.

Enquanto vários técnicos procuram apontar para os possíveis benefícios relacionados a produção de energia por usinas nucleares, assistimos em alguns países, sobretudo europeus, as discussões que nos levam a crer que esta alternativa de produção de energia possui poucas 
possibilidades de crescimento a médio e a longo prazo.

Por fim, as modalidades de geração fotovoltaica e eólica, apesar de menos prejudiciais ao meio-ambiente, ainda sofrem com o status de fontes alternativas. É importante ressaltar que atualmente não se consideram os prejuízos ambientais nos custos da energia final. A partir do momento em que esses impactos forem considerados, as chamadas "tecnologias alternativas" deverão se tornar fontes atrativas de investimento e, o aumento de sua demanda tende a reduzir seus preços.

Não existe dúvida de que o potencial disponível no Brasil, em termos de "energia limpa" (solar e eólica), é um dos maiores do planeta. A opção por formas de aproveitamento de combustíveis fósseis (gás natural) como solução para o problema de escassez vai em direção oposta à visão de um futuro com desenvolvimento sustentável.

O Brasil, que deveria aspirar à posição de liderança mundial no desenvolvimento de energias limpas, tais como eólica e a solar, decidiu-se por investir em termelétricas movidas a gás natural.

\section{Considerações finais}

Para cumprir sua função social, a escola deve contribuir para a socialização dos conhecimentos científicos. Neste sentido, é necessário que os principais temas discutidos e valorizados pela sociedade estejam sistematizados como saber escolar.

Considerando que a passagem do conhecimento científico para a sala de aula não se dá por simples processos de transmissão, procuramos, com este trabalho, apontar as principais discussões que ocorrem nos meios técnicos e acadêmicos sobre produção de energia elétrica em larga escala e a temática ambiental.

Trabalhos educativos que abordem esta temática devem, necessariamente, considerar questões históricas, econômicas, políticas, sociais e ambientais, que se mesclam e se fundem juntamente com uma análise técnica. Soma-se a isso a característica eminentemente controversa do tema, pois uma análise mais elaborada leva em conta diferentes posições defendidas por diversos grupos da sociedade, tais como discussões sobre o bemestar social, a saúde humana, o conforto individual, os ganhos econômicos, os posicionamentos políticos, éticos e ideológicos e a temática ambiental.

No entanto, devemos também considerar que a conversão do saber sistematizado pela ciência em saber escolar ainda esbarra em obstáculos inerentes à realidade da escola pública, tais como: formação atual dos professores, falta de material didático adequado, melhores condições salariais, tempo escasso para a preparação de material e das aulas, ausência de sugestões sistematizadas para se abordar o tema.

Neste sentido, é importante considerarmos que não existem fórmulas mágicas relacionadas às práticas de educação ambiental. Diante deste contexto, surge a necessidade de, além de mudanças nas condições gerais de trabalho do professor, da realização de pesquisas e de programas de ação que enfoquem a formação inicial e continuada do professor e de propostas de projetos de elaboração de material didático que conte com a participação direta de professores.

\section{Bibliografia}

BRANCO, S.M. e ROCHA A.A., Poluição, proteção e uso múltiplos de represas. São Paulo: Cetesb, 1977.

BRASIL, Ministério da Educação e do Desporto, Secretaria de Educação Fundamental. Parâmetros Curriculares Nacionais, $5^{\circ}$ a $8^{\circ}$ séries do ensino fundamental, Ciências Naturais. Brasília, 1998.

Ministério da Educação e do Desporto, Secretaria da Educação Média e Tecnológica. Parâmetros Curriculares Nacionais : ensino médio, Brasília, p. 203-277, 1998.

BRUNDTLAND REPORT Our Common Future New York, Oxford Universety Press, 1987.

BRÜGGER, P. Educação ou adestramento ambiental? Ilha de Santa Catarina: Letras Contemporâneas, 1994. $142 \mathrm{p}$.

CARVAlHO, L.M. Natureza da Ciência, Temática Ambiental e o Ensino das Ciências Naturais: o futuro professor de biologia - seus projetos e suas práticas. 1998. Relatório de Pesquisa de pós - doutorado - Instituto de Biociências - Departamento de Educação, Universidade do Estado de São Paulo. (no prelo)

Fundamental: perspectivas e
possibilidades IN : REVISTA DE EDUCAÇÃO Porto Alegre, Editora Projeto, vol. 1, n.01, jul. 1999, p. $35-39$.

$\begin{array}{llcc} & \text { Educação Ambiental e a Formação } \\ \text { de Professores. } & \text { In: OFICINA PANORAMA }\end{array}$ DE EDUCAÇÃO AMBIENTAL NO BRASIL, 2000, Brasília. Oficina Panorama de Educação Ambiental no Brasil, Brasília Ministério da Educação, Secretaria de Educação Fundamental, 2000 p.51-58.

CHAMBOULEYRON, I. Eletricidade Solar. IN Ciência Hoje, São Paulo, SBPC, vol. 9, n. 54, jun. 1989, p. 32-39.

GOLDEMBERG, J. Energia, Meio Ambinte e Desenvolvimento. São Paulo: Edusp, 1998. 235 p.

LEFF, E. Epistemologia Ambiental. São Paulo: Cortez, 2000. 240 p.

MALHEIROS, T. Histórias secretas do Brasil nuclear. Rio de Janeiro: W.V.A, 1996. 237 p.

PEREIRA, E.B. COLLE, S. A energia que vem do sol. IN Ciência Hoje, São Paulo, SBPC. vol. 22, n. 130, agosto 1997, p. 24-35. 
REIS, L.B. SILVEIRA, S. (orgs.) Energia elétrica para o desenvolvimento sustentável: introdução de uma visão multidisciplinar. São Paulo: Editora da Universidade de São Paulo, 2000. 284 p.

ROSA, L.P. TOLMASQUIM, M.T. PIRES, J.C.L. A reforma do setor elétrico no Brasil e no mundo: uma visão crítica. Rio de Janeiro: Relume Dumará, 1998. $211 \mathrm{p}$.

ROSA, L.P. HESLES, J.S.H. RODRIGUES, A.J.P. AROUCA, M.C. KOEHLER, C. PIRES, R.L.F. ARAÚJO, J.L. OLIVEIRA, A. MAGRINI, A. ALVEAL, C. BARROS, E.B.M. MOREIRA, J.G. MIELNIK, O. ROVERE, E.L. e CASTRO, A.B. Energia e Crise. Petrópolis - RJ : Vozes, 1984. 196 p.
ROSA, L.P. SIGAUD, L. MIELNIK, O. Impactos de grandes projetos hidrelétricos e Nucleares. São Paulo: Marco Zero, 1988. 200 p. SÃO PAULO, Proposta curricular para o ensino de física $2^{0}$ grau. São Paulo: Secretaria de Estado da Educação, 1992.

SAVIANI, N. Saber escolar, currículo e didática : problemas da unidade conteúdo/ método no processo pedagógico. Campinas: Autores Associados, 2000.

SILVA, L. F. A temática Ambiental e o Ensino de Física na Escola Média : a produção de energia elétrica em larga escala como um tema controverso. Araraquara, 2001 - Dissertação - (Mestrado em Educação Escolar) Universidade do Estado de São Paulo. 